\title{
A interpretación de conferencias no marco da planificación do status lingüístico: o caso galego
}

\author{
Robert Neal Baxter \\ Universidade de Vigo
}

\begin{abstract}
Resumo:
O artigo comeza cun breve repaso dunha das máis veteranas e aínda vixentes teorías da interpretación para comprobar como encaixan as especificidades da interpretación con linguas subordinadas. Tras unha exposición das diferenzas entre a tradución escrita e a interpretación oral, o artigo pasa a considerar en que medida a interpretación de conferencias pode desempeñar un papel na planificación lingüística de linguas como o galego. Aínda que se centra principalmente na planificación do status, o autor tamén considera o papel da/o intérprete como axente de divulgación de patróns lingüísticos normativizados. $\mathrm{O}$ artigo pecha cunha serie de reflexións sobre a interpretación como garantía do exercicio efectivo dos dereitos lingüísticos e apunta o seu impacto sobre a conservación da diversidade lingüística como futura liña de investigación.
\end{abstract}

\section{Palabras chave:}

Diglosia, interpretación de conferencias, planificación lingüística, estatus/prestixio, dereitos lingüísticos.

\begin{abstract}
:
The paper opens with a cursory overview of one of the most long-standing and still acknowledged interpreting theories in order to determine how it fits in with the specifics of subordinated languages. Following a description of the differences between written translation and spoken interpretation, the paper goes on to consider to what extent conference interpreting can play a role in language planning for languages such as Galizan. Although focussing primarily on status planning, the author also discusses the role of interpreters as agents for spreading standardised language norms. The article closes with a series of reflections on interpreting as a guarantee for the effective exercise of language rights, indicating its impact on the maintenance of language diversity as a future line of research.
\end{abstract}

\section{Key words:}

Diglossia, conference interpreting, language planning, status/prestige, language rights. 


\section{Introdución}

Unha das máis veteranas escolas teóricas da interpretación aínda hoxe influente, a 'teoría do sentido', liderada por Seleskovitch $(1968,1975)$ e Lederer (1981; Seleskovitch / Lederer 1989), defende a hipótese da 'desverbalización' como base da interpretación. Segundo esta tese, a estrutura lingüística superficial desmaterialízase na mente da persoa que interpreta, deixando ao descuberto o 'sentido' implícito da mensaxe orixinal que se volve reexpresar lingüisticamente noutra lingua. Deste modelo deriva unha implicación clara: ao desaparecer o envoltorio lingüístico da mensaxe para (re)transmitir o 'sentido' profundo, non se trata de 'traducir' entre linguas, entendido como mudanza lingüística. Así, o proceso interpretativo en si é sempre o mesmo, independentemente do par de linguas do que se tratar:

[...] in general [IT writers] prefer to say that the message is 'deverbalised' in the association of the text meaning with cognitive memory, and that speech is produced from these successive crystallisations of sens by an unconscious programme at a non-verbal level. [...] The model deliberately leaves the intermediate stage of cognitive processing unspecified, in contrast with IP theories which see a conceptual-semantic framework, integrated with a crosslinguistic lexicon, through which the interpreter has to find her way. (Setton 1999: 43).

Deste xeito, interpretar entre dúas linguas tipoloxicamente distantes cunha sintaxe e morfoloxía moi disimilares, como por exemplo o chucoto (endónimo лыгъоравэтльэн йилыйил), lingua polisintética da familia paleosiberiana, e unha lingua analítica como o tailandés, non suporía máis dificultades do que interpretar entre dúas linguas próximas como o neerlandés e a lingua africáner, ou mesmo entre o galego e o portugués.

No entanto, xa desde finais dos anos 1970 comezaron a se realizar investigacións de tipo empírico (Ilg 1978; Wilss 1978) que tenden a indicar que a 'desverbalización' non reflicte -cando menos sen máis- o proceso interpretativo real. Son cada vez máis os estudos que apuntan na mesma dirección, indicando que as diferenzas nas estruturas lingüísticas entre a lingua de partida (LP) e a lingua de chegada (LC), así como a direccionalidade (por exemplo do inglés para o galego e vice versa para unha falante nativa de calquera membro deste binomio), si inflúen claramente no proceso interpretativo en maior ou menor grao, o que leva á aplicación de estratexias diferenciadas en cada caso concreto:

Some theories on Interpreting tell us that interpreting is just understanding in one language and explaining in another; it is simply the transmission of the 
message as it has been intended by the original speaker. [...] We believe that this theoretical approach [théorie $d u$ sens] does not take into account either the implications that the languages involved and their direction have on the interpreting process [...] Padilla / Abril (2003: 391).

Contrariamente, pois, á hipótese da desverbalización, fica demostrado que existen factores lingüísticos e metalingüísticos que inflúen no proceso interpretativo, para alén da simple transmisión do sentido subxacente. Partindo dunha longa experiencia tanto no mundo profesional da interpretación co galego como na súa docencia, este artigo propón indagar sobre como a situación sociolingüística na que se desenvolve unha interpretación tamén pode ser un factor que incide sobre o decorrer dos procesos interpretativos. A conclusión á que chega é que non é indiferente o uso dunha lingua dominada como o galego, fronte a unha lingua dominante como o español como lingua de traballo, tendo en conta as reaccións das partes implicadas, nomeadamente a persoa que emite a mensaxe orixinal, a persoa que a interpreta e o público que recibe a mensaxe interpretada final.

Antes de proseguirmos, cómpre acrecentar un inciso para esclarecer a terminoloxía empregada, ao revestir o termo máis habitual 'lingua minoritaria' unha certa complexidade espazotemporal (Cronin 1995: 86-87), non exenta de ambigüidades e mesmo usos contraditorios, podendo abranguer casos de linguas autóctonas minorizadas como o galego, como o caso moi disimilar das linguas faladas por minorías procedentes da inmigración, como é, por exemplo, o árabe dialectal na Francia. Para evitar tales confusións, téñense acuñado varias alternativas para resaltaren aspectos concretos das linguas en cuestión, entre as que podemos destacar, por exemplo 'linguas menos traducidas' (Branchadell, A. et al. 2004). Unha vez máis, no entanto, achámonos perante un termo que se pode aplicar tanto a casos como o galego, como tamén a casos moi disimilares de linguas nacionais plenamente normalizadas que se traducen con menos frecuencia, en contraste coas linguas internacionalmente dominantes (sobre todo o inglés). Pasa algo similar cos termos 'linguas menos estendidas' ou 'menos faladas' que poden ser aplicados a linguas cun número reducido de falantes sen proxección como lingua de uso internacional, mais nunha situación sociolingüística interna estábel, como no caso do húngaro (Tóth 1991: 121).

Descartamos de partida o termo 'lingua minoritaria' para describir casos como o galego, por non ser a lingua numericamente minoritaria dentro do seu propio territorio en termos de capacidade (falantes activas/os e pasivas/os). Para evitar tales equívocos, xa desde hai varios anos no ámbito galego se encontra habitualmente o termo 'minorizada' (Fernández Rei / Santamarina Fernández 1999) para recalcar o facto de se tratar dun proceso ao que está obxecto a lingua en cuestión, máis 
que un simple trazo matemático inherente. No entanto, nós preferimos os termos 'linguas subordinadas' ou 'dominadas' (Baxter 2006) para tornar patente a relación eminentemente ideolóxica que existe entre elas e as súas respectivas 'linguas dominantes'.

Existe unha grande variabilidade en canto á situación legal das linguas subordinadas tratadas aquí dentro do ámbito europeo. O marco xurídico mesmo pode mudar para unha mesma lingua dun Estado para un outro, desde un certo amparo legal dentro dun determinado territorio (galego, vasco, catalán no Estado español), até unha falta total de recoñecemento de calquera tipo de (co)oficialidade (vasco, catalán, bretón no Estado francés), chegando, en casos extremos, a unha actitude belixerante directa ou indirectamente. Tomaremos como definición de partida aquela que recolle o Artigo 1 da Carta europea das linguas rexionais ou minoritarias:

Para os fins desta Carta: a) pola expresión "linguas rexionais ou minoritarias" entenderanse as linguas: i) faladas tradicionalmente nun territorio dun Estado por nacionais dese Estado que constitúen un grupo numericamente inferior ao resto da poboación do Estado, e ii) diferentes da(s) lingua(s) oficial(is) do Estado; non inclúe os dialectos da(s) lingua(s) oficial(is) do Estado nin as linguas dos inmigrantes (Consello de Europa 1992).

O que nos interesa aquí máis especialmente son casos como o do galego, onde existe unha clara situación diglósica (Loureiro-Rodríguez, 2007), isto é, un desequilibro entre os ámbitos de uso formais e de alto prestixio que se reservan para a lingua dominante (español), fronte ao baixo prestixio dos usos informais da lingua dominada (galego). Cabe recalcar que a existencia dun recente uso ritualizado do galego en determinados ámbitos formais tradicionalmente circunscritos ás linguas de prestixio non altera a situación sociolingüística de prestixio no seu conxunto, ficando en termos globais dentro da definición da diglosia, aínda sen se conformar exactamente ao modelo tradición stricto sensu.

Neste artigo, exponse como a interpretación de conferencias, sobre todo na modalidade simultánea, pode axudar a paliar simbolicamente este déficit de prestixio. Por outra banda, as situacións diglósicas tamén tenden a xerar un alto grao de inseguridade lingüística nas persoas que falan ou poderían falar a lingua dominada, polo que tamén se reflectirá sobre as posíbeis repercusións deste factor sobre a/o intérprete no momento de desenvolver as súas estratexias de traballo. 


\section{A tradución escrita e as linguas subordinadas}

Xa desde mediados dos anos 1980, a teoría dos polisistemas comezou a interesarse polo papel que desempeña o fenómeno da tradución nas linguas minoritarias, cando Toury (1985: 3) as describe como "débiles a respecto das linguas maioritarias das comunidades en cuestión", tese que foi desenvolvida e aplicada especificamente ao caso galego por Cruces (1993). Máis adiante, este tipo de focaxe centrada esencialmente no sistema literario comezou a deixar paso a análises de corte propiamente lingüístico, aplicadas a outras linguas minoritarias e/ou minorizadas (Zabaleta 2002).

A licenciatura de tradución e interpretación que ofrece a Universidade de Vigo desde 1992 permite cursar todos os estudos tendo por lingua de partida o galego. Isto xerou un fluxo constante e moi importante de publicacións que tratan concretamente a cuestión da tradución en galego - tanto desde o galego como para o galego-desde moitos aspectos cuantitativos e cualitativos, entre as que podemos destacar, a modo de exemplo lonxe de ser exhaustivo: Baxter (2002); Cruces (1993); Constenla Bergueiro (2008) ${ }^{1}$; García González (2002); Luna Alonso (2006); Millán-Varela (2000), etc.

Aínda que en menor medida a respecto do galego, ao longo deste período tamén se foi prestando unha atención cada vez maior ao papel normalizador da tradución como fenómeno cunha alta carga simbólica de cara á sociedade nun amplo abano de linguas subordinadas europeas, desde o vasco (Mendiguren Bereziartu 2002) e o bretón (Baxter 2006) até o catalán (Garcia Porres 2002; Xirinachs 1997), pasando polo flamengo (Meylaerts 2009) e o gaélico irlandés (Cronin 1995), etc.

Este importante corpo de investigación, que se vai perfilando como subdisciplina de seu dentro do ámbito dos estudos de tradución en simbiose coa sociolingüística, coincide en afirmar que a tradución pode desempeñar un papel fundamental nos procesos de "revitalización lingüística" co fin de inverter os procesos de "mudanza lingüística", para recollermos os termos acuñados por Fishman (1991; 2001).

Aínda que non sexa o tema central deste traballo, tamén convén recalcar que a interpretación dá visibilidade pública ás linguas subordinadas, o que fai que o público receptor tamén se torne consciente da existencia destas. Deste xeito, sería proveitoso levar a cabo un estudo máis detallado acerca do papel que desempeña

1 Entre os moitos artigos publicados por este autor, destacamos este en particular por facilitar unha bibliografía actualizada que abrangue un amplo abano de artigos e teses doutorais que tratan especificamente a cuestión da tradución literaria en galego, sobre todo desde o punto de vista diacrónico. 
a interpretación oral de cara á manter o que Bastardas-Boada $(2005 ; 2007)$ define como a 'sustentabilidade lingüística', dentro do marco conceptual da ecolingüística xa utilizada para a tradución escrita en Diaz Fouces (2005 e 2010):

[...] we are interested [in the dimension] that considers translation as an instrument to maintain diversity, i.e. the wealth of the ecolinguistic system, and therefore to resist the centripetal socioeconomic and sociocultural tensions (Diaz Fouces 2005: 99).

\section{A interpretación oral e as linguas subordinadas}

Cabe recoñecer que en moitas situacións a interpretación con linguas subordinadas e/ou minoritarias toma a forma de 'mediación lingüística' (en inglés language brokering, Morales / Hanson 2005), realizada por persoas achegadas e familiares sen formación específica como, por exemplo, o caso dunha alumna, filla de inmigrantes de primeira xeración, que interpreta entre a súa nai e a súa profesora. Agora ben, non se debe pasar por alto o facto de se levaren a cabo interpretacións formais de xeito regular realizadas por intérpretes profesionais especializadas/os nun grande abano de linguas subordinadas e/ou minoritarias, xa non só na Europa, desde o vasco (euskera) até o gales (cymraeg), pasando polo sami (sámegielat), o groenlandés (kalaallisut) e o maorí (te reo Māori $)^{2}$, etc.

Existen, aliás, moitos centros académicos que ofrecen unha formación superior específica de diferentes tipos (parcial, completa, grao ou posgrao...) para intérpretes con linguas subordinadas, desde o grao en tradución e interpretación da Universidade de Vigo que se pode cursar integramente en galego, até o catalán na Universitat Autònoma de Barcelona e na Universitat Jaume I, o vasco na Euskal Herriko Unibertsitatea/Universidad del País Vasco no Estado español, pasando polo irlandés na Ollscoil na hÉireann/National University of Ireland (Gaillimh/Galway) ou o maorí na Te Whare Wānanga o Waikato/University of Waikato, etc.

No entanto, agás unha serie limitada de excepcións illadas (Baxter 2008; Garmendia 2007; Urkia 2009), a interpretación destaca pola súa ausencia como obxecto de estudo dentro do marco da planificación lingüística, en comparación coa abundancia de estudos centrados na tradución escrita. Esta disparidade podería atribuírse ao peso que tiveron tradicionalmente as análises tradutolóxicas centradas sobre todo na produción literaria e a conseguinte aplicación da teoría dos polisistemas que

2 Inclúense os endónimos co propósito explícito de lles dar visibilidade, ao seren estas as formas que utilizan as propias comunidades de falantes para denominaren as súas linguas. 
exerceu unha notábel influencia no caso do galego. Trátase dunha focaxe que non encaixa coa interpretación, fenómeno oral que dista moito da literatura escrita e que se presta dificilmente ao mesmo tipo de análise textocéntrica, ao non deixar un rastro permanente de fácil acceso, independentemente da existencia ocasional de gravacións in situ.

Existen varios tipos de interpretación que se clasifican segundo os contextos nos que se desenvolven (xurídica ante os tribunais, médica, social para comunidades inmigrantes, de conferencias, etc.) e a modalidade que se utiliza (murmurada, consecutiva ou simultánea). Destaca a interpretación simultánea de conferencias como o tipo que goza de maior prestixio simbólico, ao precisar dun certo despregamento de medios tecnolóxicos (cabinas, auriculares, etc.) e ao estar asociada no imaxinario colectivo con institucións tales como a ONU ou a UE, unha imaxe glamourosa popularizada por filmes como $A$ intérprete (2005). Debido ao alto grao de prestixio simbólico que reviste, vai ser principalmente a interpretación simultánea de conferencias e congresos o tipo que encadre as reflexións que se verten sobre a función normalizadora -entendida como a reequilibración do prestixio relativo para superar a diglosia- da interpretación para linguas subordinadas como a galega, sen que iso implique que as outras modalidades non cumpran este mesmo papel.

O trazo definitorio sine qua non que distingue a interpretación oral da tradución escrita radica na súa 'inmediatez': "Within the conceptual structure of Translation [i.e. all translation and interpretation-related phenomena], interpreting can be distinguished from other types of translational activity most succinctly by its immediacy." (Pöchhacker 2004: 10). Así, mentres algunhas das conclusións sacadas do estudo e análise do papel que desempeña a tradución na planificación de status/ prestixio e a conseguinte normalización de linguas subordinadas (Diaz Fouces 2005: 99) son igualmente válidas para a interpretación, non se poden extrapolar de xeito mecánico á interpretación.

O que isto implica na práctica é que o/a tradutor/a pode tirar un proveito estratéxico do lapso de tempo que transcorre entre a produción do texto traducido e o momento do seu consumo para engadir explicacións, notas a rodapé, etc. Tamén permite a posibilidade de utilizar xiros ou terminoloxía talvez menos familiares, ao saber que a persoa que le sempre poderá 'conxelar' a tradución no tempo para volver ler algún fragmento ou para procurar algunha información complementaria nunha fonte externa (dicionarios, enciclopedias, etc.). Pola contra, as e os intérpretes non contan con esta extemporalización e deben procurar que o seu primeiro borrador sexa suficientemente claro e comprensíbel, sen que exista moita marxe para a inclusión de esclarecementos a maiores: 
[...] there is one important macroscopic difference and this is the spatiotemporal unity within which the text or speech is delivered and the simultaneous interpreting performed, compared to a written translation which is always carried out after a temporal delay and in a different environment from the one which produced the source text. Even though the two tasks are comparable in their objectives, the information-processing load is greater and the possibility of corrections is reduced in the simultaneous mode. [...] The strategies used in translation and interpreting will thus differ in this specific respect (Riccardi 1996: 213).

Co obxectivo de acadar a máxima funcionalidade posíbel para o seu texto traducido dentro do marco do seu impacto inmediato, a/o intérprete procurará en todo o momento manter unha expresión fluída e coherente, para suscitar no seu público un sentido de confianza, e unha transmisión clara e comprensíbel á primeira escoita. Tomando en conta estas prioridades dentro do contexto específico da interpretación, mentres toman as necesarias medidas para non terxiversaren os contidos, estilo e intención do orixinal, as e os intérpretes tenden a orientar a súa estratexia xeral cara a conseguiren a máxima 'aceptabilidade' no canto de procuraren a máxima 'adecuación': “[...] whereas adherence to source norms determines a translator's adequacy as compared to the source text, subscription to norms originating in the target culture determines its acceptability." (Toury 1995: 56-57).

Optar por estratexias claramente orientadas a conseguiren un alto grao de adecuación inmediata para o texto traducido a respecto do público receptor tórnase unha preocupación aínda maior para quen interpreta con linguas subordinadas, debido ao elevado número de interferencias lingüísticas por parte da lingua dominante correspondente (Diaz Fouces 2005: 96). A inseguridade lingüística característica de situacións diglósicas funciona como factor agravante, levando ao risco de o público non estar familiarizado coa terminoloxía galega cando difire da española. Por exemplo, nun congreso médico (ámbito particularmente impermeábel ao uso do galego) onde as e os participantes galegofalantes estarán probabelmente máis familiarizados coa terminoloxía en inglés que en español debido á penetración do inglés como lingua mundial da ciencia, sen falar xa do galego. Así, un público especializado probabelmente non coñecerá ou resultaranlle estraños ou mesmo erróneos termos anatómicos como 'cartilaxe', 'medula', 'cranio', 'pulso', 'virilla', etc.

Para colocarmos o dilema en termos máis claros, podémonos referir ao hipotético caso dunha interpretación cara ao bretón. No caso do galego, existe unha proximidade lingüística relativamente estreita a respecto da súa correspondente lingua dominante (español), polo que a maioría dos termos descoñecidos poden entenderse en galego sempre e cando houber unha certa vontade por parte dun/ha receptor/a máis 
diglósico/a. No entanto, no caso do bretón existe unha brecha enorme a respecto do francés e, por moito que a terminoloxía técnica moderna parta en grande medida do principio da 'internacionalización' (exemplos: mediaoù 'medios de comunicación'; ekologiezh 'ecoloxía'; sokiopsikologiezh, 'sociopsicoloxía'; molekulenn, 'molécula', etc.), a división que existe entre un rexistro formal depurado e o rexistro oral da fala popular pode facilmente tornar incomprensíbel un texto interpretado que non tivese este factor en conta.

Por paradoxal que poida parecer, até certo punto, a interpretación cara ao galego ten certos trazos en común coa interpretación cara ao inglés no mercado freelance onde tende a haber unha porcentaxe moi alta do público receptor que non o fala como primeira lingua e na que non é necesariamente plenamente competente no seu uso ${ }^{3}$. En ambos os casos, calquera intérprete que pretenda que a súa mensaxe chegue de xeito inmediato e eficaz (o propósito principal da interpretación) non pode obviar este tipo de factores limitadores.

Polo tanto, en todo o momento a/o intérprete que traballa con linguas subordinadas socialmente non normalizadas -situacións diglósicas de desequilibrio de prestixio e ámbitos de uso- ten que estabelecer prioridades para equilibrar a súa dupla función, iso é, o seu papel explícito como mediador (función xeral como intérprete) e o seu papel implícito como axente de planificación lingüística (función específica como intérprete de galego).

Aquelas e aqueles intérpretes que traballan habitualmente co galego, sobre todo cando contan cunha formación académica específica, tenden a ser moi conscientes do seu papel como axentes de planificación lingüística. Así, poden optar por colocar este papel por encima do seu papel comunicativo ao non quereren renunciar a un uso correcto da linguaxe fronte a un percibido déficit de competencia lingüística por parte do público receptor, mesmo se, ás veces, iso podería implicar unha mingua na efectividade da función puramente comunicativa inherente ao proceso tradutivo/interpretativo. Estas situacións incluirían o uso sistemático de recursos pouco habituais no galego coloquial actual como son os infinitivos flexionados e o futuro do subxuntivo xunto con léxico depurado, por exemplo: 'desafiuzamento', 'endebedamento', 'taxas de xuro', 'desenvolver', 'investidor', 'doador', 'colidir', 'recruar', fronte ás formas españolas: castrapizadas 'desahucio', 'endeudamento', 'tipos de interese', 'desarolar', 'inversor', 'doante', 'colisionar', 'recrudecer', etc.

3 Cabe distinguir neste respecto o inglés, por un lado, que ten unha proxección moito maior como lingua franca internacional, polo que concorren habitualmente en congresos internacionais non nativos que se expresan mal que ben nesta lingua, das outras linguas consideradas 'maiores' (español, francés, portugués...) que, malia ao seu historial colonial que fai que teñan un rango 'internacional', apenas se utilizan como lingua franca por falantes non nativos neste tipo de situacións. 
A cuestión que se levanta é de orde deontolóxica, e a cada intérprete corresponde determinar en cada momento até que punto está disposta/oa 'sacrificar' conscientemente un certo grao de corrección lingüística en prol de garantir a comprensión do texto traducido de xeito inmediato por parte do público receptor. En todo caso, sempre que a persoa que interpreta opte por recoñecer e cumprir o seu papel de axente de planificación lingüística, as decisións que tomar dependerán das inferencias que formula acerca do dominio lingüístico do público receptor e as súas posíbeis reaccións fronte a unha interpretación en galego. Deste xeito, por exemplo, a interpretación podería integrar máis 'lusismos' e outros recursos cultos menos usuais (aceptados ou non pola normativa ILG-RAG) en conferencias patrocinadas por determinados departamentos universitarios en eventos organizados por organismos ideoloxicamente proclives ao reintegracionismo, por exemplo forzas políticas ou sindicais nacionalistas, especialmente ao coincidir cun público lusófono do que unha interpretación organizada pola actual Xunta de Galiza, que tende a preferir (mesmo de xeito explícito de cara á persoa encargada da interpretación) un galego 'normativo', sendo estes os clientes máis habituais que contratan interpretacións en galego.

Finalmente, aínda que este artigo está centrado na planificación do status, por outra banda tamén cabe recoñecer que a interpretación ten un potencial moi grande para a planificación do corpus, ao expor os diversos públicos a usos lingüísticos correctos como o único xeito de paliar as eivas existentes, fuxindo de españolismos innecesarios. Mais, en prol de manter o difícil equilibrio co aspecto comunicativo do seu labor, a persoa encargada da interpretación debe gañar a confianza do seu público mediante unha expresión segura e fluída.

\section{A interpretación e a planificación do status}

Pode parecer lóxico pensar que a función principal, se non a única, da interpretación consiste en facilitar unha mediación interlingüística, iso é, a súa función comunicativa. Así, ao definir a interpretación, Pöchhacker (2004: 10) indica que: “[...] interpreting is performed 'here and now' for the benefit of people who want to engage in communication across barriers of language and culture”.

Unha interpretación que non cumprir con esta función comunicativa de xeito eficaz e áxil sería considerada - con toda a razón- unha má interpretación. Mais, tamén non se deben obviar outros aspectos que entran en xogo especificamente no caso de linguas subordinadas como o galego e que condicionan as posíbeis funcionalidades da práctica interpretativa, sobre todo dentro do marco de congresos internacionais. Así, a interpretación con linguas minoritarias debe cumprir a función comunicativa primordial ao igual que para a interpretación con linguas dominantes plenamente 
normalizadas, para alén de cumprir cunha outra serie de funcións moi diferentes daquelas realizadas por intérpretes que traballan con linguas normalizadas (agás o caso específico do inglés como lingua franca antes comentado).

De facto, cabe recoñecer que o uso dunha lingua subordinada nunha interpretación a maiores ou no canto da correspondente lingua dominante sempre é froito dunha decisión política máis que propiamente comunicativa, na medida en que un público receptor do galego sería igualmente capaz de entender o mesmo texto interpretado cara ao español. A decisión de incluír unha lingua subordinada como lingua de traballo corresponde, pois, a unha clara vontade de planificación lingüística:

[...] we have to acknowledge that even as a communicative activity, translation is not always associated with a lack of understanding. When a given company makes the decision to have its advertisements or the labels of its products translated into the minority language of a state, such decision [Sic.] is not motivated by the inability of the recipients to understand the major language (García González 2005: 107).

A pesar de tratar de textos literarios escritos, as seguintes reflexións de Woodsworth acerca das implicacións políticas fronte á función comunicativa no que se refire á tradución cara a linguas subordinadas son igualmente válidas para a interpretación, tanto máis á vista do marco de alto prestixio no que se desenvolve a interpretación de conferencias:

Communication is even less of an issue in these two instances because virtually none of the speakers of Scots and Romansch are monolingual. Thus, translation is not 'necessary', strictly speaking. [...] Instead, it is an activity with significant institutional, political and ideological implications, which can be highly instructive for our understanding of translational phenomena in general (Woodsworth 1996: 213).

Ainterpretación de conferencias na modalidade simultánea supón un gasto económico importante. ${ }^{4}$ Por este motivo, téndese a limitar o seu uso a eventos que dispoñen dun orzamento elevado, o que fai que estes eventos sexan percibidos como de alto

4 A tarificación varía enormemente, suxeita ás leis de oferta e procura e coa prohibición de establecer tarifas recomendadas para non contravir a competencia no mercado 'libre', o que leva, inexorabelmente, a una infravalorización remunerativa da interpretación. Sexa como for, a título indicativo, a Asociación Galega de Profesionais da Tradución e da Interpretación (AGPTI) recomendaba no ano 2011 unha tarifa de $450 €$ por xornada por intérprete ( 8 horas, modalidade de simultánea), polo que o total por cabina, sempre con 2 intérpretes, ascende a $1044 €$ por día (IVE incluído), sen contar cos gastos que poden ocasionar o alugueiro de cabinas móbeis, o salario dunha persoa encargada dos aspectos técnicos, etc. 
prestixio. Do mesmo xeito, ao nivel simbólico, calquera conferencia que dispón dun servizo de interpretación pasará a ser considerada de rango 'internacional' e 'importante'. Así, a visibilidade que outorga a interpretación a calquera lingua subordinada neste tipo de situacións tamén vai repercutir positivamente sobre o status desas linguas. Nunha palabra, só se utilizan linguas 'importantes' en situacións 'importantes', rompendo, así, cos esquemas da diglosia onde as linguas subordinadas fican relegadas a espazos de uso de baixo prestixio.

A simple existencia do galego no abano de linguas dispoñíbeis nun congreso internacional ten o potencial de facer mudar as percepcións e inverter os prexuízos cara a el creados pola inseguridade lingüística instaurada en moitas e moitos galegofalantes, ao colocalo no mesmo nivel que as 'grandes' linguas internacionais:

Translation is an effective tool to change user's perception of the symbolic and practical value of their own language, as a language into which translations are made is considered a useful one. [...] an effective management of translation practices leads minorised languages to assume attributes of the languages of the upper level (Diaz Fouces 2005: 102).

Debido á inmediatez como trazo característico da interpretación, sumado á súa inserción directa nun contexto de alto prestixio, as observacións de Diaz Fouces acerca da tradución escrita son aínda máis pertinentes no caso da interpretación simultánea de conferencias.

Cómpre, pois, aproveitar as posibilidades que ofrece este enorme potencial simbólico que representa a interpretación cara ao galego para contrarrestar os actuais prexuízos lingüísticos que empecen a súa efectiva normalización. Como ben indica Toury (1985: 4), a cuestión de integrar o galego sistematicamente na selección de linguas que se ofertan quer na tradución, quer na interpretación é de corte político e ideolóxico máis que comunicativo, mais sempre sabendo que en ningún caso supón unha mingua da función comunicativa: "A precondition for success [...] is a favourable 'ideological climate' of enhancing the prestige of the minority language and the self-esteem of its speakers."

Por todo o anteriormente exposto, deberíase avogar por integrar o galego como lingua de interpretación nos congresos que se desenvolven na Galiza como un elemento integral da política de planificación de status (García González 2005: 111 ), asumindo o custo que iso supón como un investimento necesario, actuando ao nivel simbólico para contribuír a paliar os desequilibrios existentes a respecto do español. 


\section{A interpretación e o exercicio dos dereitos lingüísticos}

Para alén do alto valor simbólico que reviste o uso do galego como lingua de chegada (interpretación cara ao galego) que realza o seu status para o público galegofalante receptor, ofrecer a posibilidade do uso do galego como lingua de partida para as persoas que participan (interpretación desde o galego) serve para garantir o exercicio real do dereito lingüístico básico de poder expresarse libremente e con total normalidade na lingua propia da Galiza en calquera ámbito.

Existe un importante volume de literatura acerca da interpretación comunitaria como ferramenta para garantir o acceso e o exercicio efectivo dos seus dereitos a membros de comunidades inmigrantes. Por exemplo, Snelling (2002: ix) indica que a interpretación pode resultar esencial para que falantes de linguas como o hindi, o urdú ou o árabe sen competencias na lingua dominante do país se poidan desenvolver plenamente cos dereitos que lles amparan no Reino Unido e integrarse na sociedade británica como cidadá(n)s de pleno dereito.

A situación destes grupos lingüísticos non é totalmente extrapolábel á situación que se dá na Galiza, onde a ausencia do galego non supón unha barreira comunicativa, ao ser o conxunto da poboación galega funcionalmente bilingüe en español. Cabe recoñecer, no entanto, o valor da interpretación como elemento que facilita o exercicio dos dereitos básicos, que abranguen tamén os dereitos lingüísticos, polo que Skutnabb-Kangas e Phillipson (1994) falan de "dereitos humanos lingüísticos", como concepto unitario.

Para alén de simples dereitos 'morais', é importante sinalar que os dereitos lingüísticos están recollidos como tal nun amplo abano de textos de ámbito nacional e internacional, desde a propia Lei de Normalización Lingüística galega (Parlamento de Galiza 1983) até a Declaración sobre os dereitos das persoas pertencentes a minorías nacionais ou étnicas, relixiosas e lingüísticas (Nacións Unidas 1992), pasando pola Carta europea das linguas rexionais ou minoritarias (Consello de Europa 1992) e a Declaración universal dos dereitos lingüísticos, auspiciada pola UNESCO (Comité de seguimento DUDL 1996).

Aínda que os dereitos lingüísticos non son tan esenciais para a supervivencia como son, por exemplo, o dereito á auga ou á sanidade, si son esenciais para conservar a cultura inmaterial de comunidades constituídas ao longo da historia, unidas por unha mesma identidade lingüística.

A visibilización do galego mediante a posibilidade do seu uso por parte das persoas que participan nun congreso internacional pode, grazas ao valor simbólico de prestixio alto que se lle outorga, animar galegofalantes a se expresaren nesta súa 
lingua que, doutro xeito, recusarían facer por inseguridade lingüística ou simplemente porque non se lles ocorrería que o galego se puidese usar de xeito natural en tales contextos. Axuda, así, a romper os esquemas diglósicos que entorpecen o pleno desenvolvemento do galego como lingua normal en todos os ámbitos, incluídos os formais e ante persoas distinguidas.

En definitiva, en casos como o galego, ofrecer servizos de interpretación en linguas subordinadas, independentemente da capacidade das e dos participantes a respecto da lingua dominante ou outras linguas internacionais, pode servir para ir pechando a brecha que a miúdo existe entre as proclamas oficiais do recoñecemento tácito no papel dos dereitos lingüísticos e a efectivización dos mesmos por parte daquelas persoas que desexan exercelos e vivir plenamente na súa lingua, pois un dereito que non se pode exercer na realidade deixa de ser un dereito e pasa a ser un simple desideratum.

\section{Conclusións}

O uso das linguas subordinadas europeas nunca é estritamente necesario desde o punto de vista puramente comunicativo, ao coexistiren todas elas nos seus respectivos territorios cunha lingua dominante coa que toda a poboación é funcionalmente bilingüe. En tempos de crise, os argumentos puramente utilitaristas impóñense por encima de calquera outro tipo de consideración, polo que se tende a ir reducindo cada vez máis o campo de uso das linguas minorizadas entendidas como 'luxos superfluos'.

Fronte a esta visión reducionista, cabe recoñecer a interpretación como unha ferramenta que trae consigo unha serie de vantaxes importantes que van moito máis alá de facilitar a comunicación, función, por outra parte, coa que cumpren linguas como o galego a par de calquera outra.

Investir na interpretación co galego contribúe á planificación lingüística, sobre todo ao realzar simbolicamente o seu prestixio (planificación de status), mais tamén axudando a difundir un uso correcto da linguaxe (planificación de corpus). Por outra banda, serve para garantir o pleno exercicio dos dereitos lingüísticos recollidos nos diferentes textos internacionais e nacionais.

Finalmente, para alén xa dos réditos ao nivel local, ao nivel global permite expor un importante número de persoas descoñecedoras da realidade da rica diversidade lingüística da Galiza ou de calquera outro país con lingua propia á existencia destas linguas, abrindo así unha futura vía de investigación dentro do marco conceptual da ecolingüística. 


\section{Bibliografía}

Bastardas-Boada, A. (2005): "Linguistic Sustainability and Language Ecology", Language \& Ecology, 1(4). Publicación en liña: http://www.ecoling.net/ Sustainability.pdf [consult. 15/11/2011].

Bastardas-Boada, A. (2007): "Linguistic Sustainability for a Multilingual Humanity”, Glossa. -An Interdisciplinary Journal, 2(2). Publicación en liña: http://bibliotecavirtualut.suagm.edu/Glossa/Journal/vol2num2/center2.htm [consult. 21/12/2011].

Baxter, R. N. (2002): "El paper de la traducció en la consolidació de la percepció social del gallec como a Abstandsprache", Quaderns. Revista de Traducció 7, 167-181.

Baxter, R. N. (2006): "Translation for Public Consumption in Subordinated Language Communities: The Case of Breton”, en Parada, A. / Diaz Fouces, Ó. (eds.), Sociology of Translation, 11-36 (Vigo: Universidade de Vigo).

Baxter, R. N. (2008): “A interpretación simultánea e consecutiva e a normalización do galego", Longa Lingua 12, 33-37.

Branchadell, A. / West, L. M. (2004): Less Translated Languages (Amsterdam/ Philadelphia: John Benjamins).

Comité de seguimento da Declaración Universal de Dereitos Lingüísticos (DUDL) (1996): Declaración universal dos dereitos lingüísticos, auspiciada (Barcelona: PEN Club Internacional e CIEMEN). Dispoñíbel en http://www.linguisticdeclaration.org/versions/gallec.doc [consult. 12/05/2012].

Constenla Bergueiro, G. (2008): "Panorámica general de la traducción literaria en gallego (1975-2005)", en Camps, A. / Zybatow, L. (eds.), Traducción $e$ interculturalidad. Actas de la Conferencia Internacional 'Traducción e Intercambio Cultural en la Época de la Globalización', 103-108 (Frankfurt am Main: Peter Lang).

Consello de Europa (1992): Carta europea das linguas rexionais ou minoritarias (Estrasburgo: Consello de Europa). Dispoñíbel en http://www.coe.int/t/dg4/ education/minlang/textcharter/Charter/Charter_gal.pdf [consult. 12/05/2012].

Cronin, M. (1995): “Altered States: Translation and Minority Languages”, TTR: traduction, terminologue, rédaction 8(1), 85-103.

Cruces, S. (1993): “A posición da literatura traducida no sistema literario galego", Boletín Galego de literatura 10, 59-65. 
Diaz Fouces, Ó. (2005): “Translation policy for minority languages in the European Union. Globalisation and resistance", en Branchadell, A. / West, L.W. (eds.), Less Translated Languages, 95-104 (Amsterdam/Philadelphia: John Benjamins).

Diaz Fouces, Ó. (2010): “(Eco)linguistic Planning and Language-exchange management", MONTI: Monografías de traducción e interpretación 2, 283313.

Fernández Rei, F. / Santamarina Fernández, A. (eds.) (1999): Estudios de sociolingüística románica. Linguas e variedades minorizadas (Santiago de Compostela: Universidade de Santiago de Compostela).

Fishman, J. A. (1991): Reversing language Shift: Theory and Practice of Assistance to Threatened Languages (Clevedon: Multilingual Matters).

Fishman, J. A. (ed.) (2001): Can Threatened Languages Be Saved? Reversing Language Shift, Revisited: A 21st Century Perspective (Clevedon: Multilingual Matters).

Garmendia, M. (2007): "Eskarmentuak erakutsi diguna. Interpretazioaz bi hitz" [Interpretación: achegas desde a experiencia], Senez 32, 217-224.

García González, M. (2002): “El paper de la traducció en la normalització de la llengua gallega”, en Diaz Fouces, Ó. / García González, M. / Costa Carreras, J. (eds.), Traducció i dinàmica sociolingüística, 55-84 (Barcelona: LLibres de l'índex).

García González, M. (2005): “Translation of minority languages in bilingual and multilingual communities", en Branchadell, A. / West, L.W. (eds.), Less Translated Languages, 105-123 (Amsterdam/Philadelphia: John Benjamins).

Garcia Porres, Y. (2002): "El paper de la traducció en el procés de normalització de la llengua catalana. Una perspectiva sociològica”, en Diaz Fouces, Ó. / García González, M. / Costa Carreras, J. (eds.), Traducció i dinàmica sociolingüística, 19-54 (Barcelona: LLibres de l'índex).

Ilg, G. (1978): “De l'allemand vers le français: l'apprentissage de l'interprétation simultanée", Parallèles 1, 69-99.

Lederer, M. (1981): La traduction simultanée (Paris: Minard Lettres Modernes).

Loureiro-Rodríguez, V. (2007): “Are Galicians bound to diglossia? An analysis of the nature, uses and values of standard Galician", en Potowski, K. / Cameron, R. (eds.), Spanish in Contact: Policy, Social and Linguistic Inquiries, 119-132 (Amsterdam/Philadelphia: John Benjamins). 
Luna Alonso, A. (2006): "La traducción de las culturas minorizadas. El caso gallego", Senez 30, 151-165.

Mendiguren Bereziartu, X. (2002): "Développement de la traduction en langue basque", Senez 24, 11-29.

Meylaerts, R. (2009): “'Et pour les flamands, la même chose': quelle politique de traduction pour quelles minorités linguistiques?”, Meta: Translator's Journal, 54(1), 7-21.

Millán-Varela, Carmen (2000): "Translation, Normalisation and Identity in Galicia(n)", Target 12(2), 267-282.

Morales, A. / Hanson, W.E. (2005): "Language Brokering: An Integrative Review of the Literature", Hispanic Journal of Behavioral Sciences 27(4), 471-503.

Nacións Unidas (1992): Declaración sobre los derechos de las personas pertenecientes a minorías nacionales o étnicas, religiosas $y$ lingüísticas. (Xenebra: Oficina de Información e de publicacións OACDH). Dispoñíbel en http://www2.ohchr.org/spanish/law/minorias.htm [consult. 12/05/2012].

Padilla, P. / Abril, M.I. (2003): "Implicaciones de la direccionalidad inglés-español en la adquisición de la técnica de interpretación simultánea”, en Kelly, D. I Martin, A. / Nobs, M-L. / Sánchez, D. / Way, C. (eds.), La direccionalidad en la traducción e interpretación. Perspectivas teóricas, profesionales y didácticas, 391-406 (Granada: Atrio).

Parlamento de Galiza (1983): "Lei 3/1983, do 15 de xuño, de Normalización Lingüística galega", Diario Oficial de Galicia núm. 84, do 14.7.1983. Santiago de Compostela: Parlamento de Galiza. Dispoñíbel en http://www.xunta.es/ linguagalega/arquivos/Ref.xral-2.pdf [consult. 12/05/2012].

Pöchhacker, F. (2004): Introducing Interpreting Studies (London \& New York: Routledge).

Riccardi, A. (1996): "Language-specific strategies in simultaneous interpreting”, en Dollerup, C. / Appel, V. (eds.), Teaching Translation and Interpreting 3. New Horizons. Papers from the Third Language International Conference, 213-222 (Amsterdam/Philadelphia: John Benjamins).

Seleskovitch, D. (1968): L'interprète dans les conférences internationales: problèmes de langue et de communication (Paris: Minard Lettres Modernes).

Seleskovitch, D. (1975): Langage, langues et mémoire: étude de prise de notes en interprétation consécutive (Paris, Minard, Lettres Modernes). 
Seleskovitch, D. / Lederer, M. (1989): Pédagogie raisonnée de l'interprétation (Paris: Didier Erudition).

Setton, R. (1999): Simultaneous Interpretation. A cognitive-pragmatic analysis (Amsterdam/Philadelphia: John Benjamins).

Skutnabb-Kangas, T. / Phillipson, R. (eds.) (1994): Linguistic Human Rights. Overcoming Discrimination (Berlín/Nova York: Mouton de Gruyter).

Snelling, D.C. (2002): "Foreword”, en Garzone, G. / M. Viezzi, M. (eds.), Interpreting in the $21^{\text {st }}$ Century. Challenges and opportunities. Selected papers from the $1^{\text {st }}$ Forli Conference on Interpreting Studies: ix-x (Amsterdam/Philadelphia: John Benjamins).

Tóth, É. (1991): "La traducción literaria de lenguas minorizadas a lenguas de mayor difusión", Senez 7 (2-3), 129-146.

Toury, G. (1985): “Aspects of translating into minority languages from the point of view of translation studies" Multilingua 4(1), 3-10.

Toury, G. (1995): Descriptive Translation Studies and Beyond (Amsterdam/ Philadelphia: John Benjamins).

Urkia, J. (2009): “Interpretazioa. Nora goaz, norantz joan nahi dugu?" [Interpretación: A onde imos, a onde queremos ir?], Senez 37, 183-196.

Wilss, W. (1978): "Syntactic anticipation in German-English simultaneous interpretation", en Gerver, D. / Sinakao, W.H. (eds.), Language Interpretation and Communication. Proceedings of the NATO Symposium on Language Interpretation and Communication, 335-343 (New York: Plenum Press).

Woodsworth, J. (1996): “Translation and the Promotion of National Identity", Target $8(2), 211-238$.

Xirinachs, M. (1997): "La traducción como instrumento de normalización lingüística", Senez 19, 25-40.

Zabaleta, J.M. (2002): “Traduction et normalisation linguistique”, Senez 24, 181192. 